\title{
Effect of cellulose, hemicellulose and lignin contents on pyrolysis and combustion of natural fibers
}

\author{
G. Dorez, L. Ferry*, R. Sonnier, A. Taguet, J.-M. Lopez-Cuesta \\ Centre des Matériaux C2MA, Ecole des Mines d'Alès, 6 Avenue de Clavières, F-30319 Ales Cedex, France
}

\begin{abstract}
A B S T R A C T
This paper investigates the effects of cellulose, hemicellulose and lignin on the pyrolysis and combustion of several natural fibers (cotton linter, flax, hemp, sugar cane, bamboo and coir). Different parameters have been selected to study the relations between chemical composition, pyrolysis and combustion: char yield (Res), effective heat of combustion (EHC), activation energy of combustion (Ea) and $\mathrm{CO} / \mathrm{CO}_{2}$ ratio during cone calorimeter test. A correlation was found between these parameters and the lignin content in a large range of composition. The natural fibers with high content of lignin exhibit high char yield, high $\mathrm{EHC}$, high Ea and low $\mathrm{CO} / \mathrm{CO}_{2}$ ratio. However, a particular behavior was observed at low lignin/cellulose ratio. The presence of a low content of lignin with a high content of cellulose affects the degradation pathway of the latter and leads to charring and to incomplete combustion of these fibers, limiting their contribution to the heat evolved during burning.
\end{abstract}

Keywords:

Natural fibers

Cellulose

Xylan

Lignin

Pyrolysis

Combustion

\section{Introduction}

Natural fibers/polymer biocomposites are emerging as a viable alternative to traditional glass reinforced composites. Many natural fibers are now available as reinforcement for polymers (flax, hemp, jute, coir, kenaf, sisal, abaca,...) [1,2]. It is generally recognized that these fibers exhibit some benefits compared to glass fibers: low density, good specific mechanical properties, non-abrasive properties, low acoustic and thermal conductivity, biosourcing and biodegradable. Conversely, their wide use in industrial applications remains limited by some drawbacks that must be overcome: variability of the dimensional and structural properties (e.g. the density, the diameter, the length, the cellulose rate,...), water sensitivity, poor compatibility with polymer matrix, low thermal sensitivity and high flammability [2-4]. In some sectors such as building, public transportation, electrical equipments, reaction to fire is a key specification. Therefore, the use of biocomposites in those sectors requires that their flame retardancy is improved. As organic compound and significant component of biocomposites, natural fibers are an important source of fuels during a fire. Moreover, natural fibers can be used as char, promoting a barrier effect [4-6]. Hence, the pyrolysis and the combustion of natural fibers must be

\footnotetext{
* Corresponding author. Tel.: +33 466785358

E-mail address: laurent.ferry@mines-ales.fr (L. Ferry).
}

accurately investigated to better understand their contribution to a fire scenario.

The pyrolysis of lignocellulosic biomass has been the subject of many papers in the literature [7-10]. The general topic of these papers is the thermochemical conversion of biomass to generate heat. This subject differs to some extent from the thermal behavior of the biomass during an accidental fire in so far as decomposition occurs generally in well controlled conditions (temperature and atmosphere). However some useful information can be extracted from this literature to apprehend the burning behavior of natural fibers. Thermogravimetric analysis (classical or modulated) is the main technique used in these studies. In some cases, TGA is coupled with FTIR analysis. Several papers investigated the pyrolysis mechanisms of the three main components of biomass (cellulose, hemicellulose and lignin) [11-13]. The pyrolysis of hemicellulose and cellulose occurs quickly with a weight loss from 220 to $315^{\circ} \mathrm{C}$ for hemicellulose and from 315 to $400^{\circ} \mathrm{C}$ for cellulose. Lignin decomposes over a wider range of temperature (from 160 to $900^{\circ} \mathrm{C}$ ) and generates a high char yield [13]. Some of these studies concluded that the pyrolysis of any biomass is the superposition of the three main components decomposition [13-16]. However, contradictory results were also mentioned. Pasangulapati et al. studied the pyrolysis and gas evolution profiles of four biomass materials with different composition in cellulose, hemicellulose and lignin [11]. They observed that the three components have weight loss profiles and activation energies very different. However, no significant difference was observed on the same parameters for the 
Table 1

Chemical composition of the different natural fibers used in this work.

\begin{tabular}{|c|c|c|c|c|c|c|}
\hline Fibers & Cellulose (\%) & Hemicellulose (\%) & Lignin (\%) & Soluble (\%) & Ash (\%) & Morphology (length ${ }^{\mathrm{a}}$ ) \\
\hline Cellulose & 100 & 0 & 0 & 0 & 0 & Microfiber ( $\mu \mathrm{m})$ \\
\hline Lignin & 0 & 0 & 100 & 0 & 0 & Powder $(\mu \mathrm{m})$ \\
\hline Xylan & 0 & “100” & 0 & 0 & 0 & Powder $(\mu \mathrm{m})$ \\
\hline Cotton linter & $89.7(0.4)$ & $1.0(0.3)$ & $2.7(0.2)$ & $6.3(0)$ & $0.3(0.1)$ & Microfiber $(\mathrm{cm})$ \\
\hline Flax & $80(1)$ & $13(1)$ & $2(1)$ & $4(1)$ & $1(1)$ & Fiber $(\mathrm{mm})$ \\
\hline Hemp & $74.1(0.5)$ & $7.6(0.3)$ & $2.2(0.2)$ & $15.8(0.4)$ & $0.3(0.1)$ & Long fiber (cm) \\
\hline Sugar cane & $51.8(0.4)$ & $27.6(0.8)$ & $10.7(0.4)$ & $9.1(0.9)$ & $0.8(0.1)$ & Fiber $(\mathrm{mm})$ \\
\hline Bamboo & $54.6(0.6)$ & $11.4(0.6)$ & $21.7(0.3)$ & $10.6(0.1)$ & $1.6(0.1)$ & Fiber $(\mathrm{mm})$ \\
\hline Coconut & $51.3(1.1)$ & $11.7(0.7)$ & $30.7(0.4)$ & $5.7(0.4)$ & $0.6(0.1)$ & Long fiber (cm) \\
\hline
\end{tabular}

a The length is an order of magnitude.

four biomass materials (switchgrass, wheat straw, redcedar, dried distilled grains with solubles). However, some changes could be noticed about the released gases. The lignin-rich biomass released a larger amount of methane.

Many of the previously mentioned papers studied also combustion of biomass by switching the purge gas from nitrogen to air in TGA experiments [7-10,12]. The thermal degradation studied in these conditions corresponds actually to oxidative pyrolysis. Cheng et al. compared the oxidative and non-oxidative pyrolysis of a woody biomass with those of microcrystalline cellulose, xylan and lignin, extracted by organosolv process, using a modulated-TGA [12]. The presence of oxygen leads to a second decomposition step at high temperature which corresponds to char oxidation. For xylan, no significant difference is observable. Lignin under air starts to decompose at higher temperature and the mass residue at $600^{\circ} \mathrm{C}$ is negligible. Many data are available on decomposition temperature and activation energy for oxidative and non-oxidative pyrolysis of various biomasses [17].

If several papers are now available on the fire behavior of composites containing natural fibers $[5,18,19]$, the literature on the combustion characteristics (time to ignition, heat release,...) of natural fibers themselves in a fire scenario is almost non-existent. One of the only papers on the subject was written by Kozlowski et al. [4]. They investigated the flammability of natural fibers using cone calorimeter. They observed that the lignin rich bast fibers (flax, hemp) exhibit a lower heat release rate than leaf fibers (cabuya and abaca). So a high content of cellulose could increase the flammability of the fibers.

The objective of the present work is to determine some of the main parameters of pyrolysis and combustion of natural fibers (cotton linter, flax, hemp, sugar cane, bamboo, coir) involved in the development of a fire. It will be attempted to relate these characteristics to the fiber composition. For this purpose, cellulose, xylan (main component representative of hemicellulose) and lignin will be used as model for the main components of biomass. The contribution to pyrolysis and combustion will be evaluated using the four following parameters: the char yield (Res), the effective heat of combustion (EHC), the activation energy of combustion and the evolution of $\mathrm{CO} / \mathrm{CO}_{2}$ ratio during a cone calorimeter test.

\section{Experimental}

\subsection{Materials}

Cellulose (Arbocel BC100, from Rettenmeier \& Söhne GMBH), xylan extracted from beechwood (Sigma Aldrich), which is the main component of hemicellulose [20] and an organosolv lignin kindly supplied by the Centre de Mise en Forme des Matériaux (CEMEF-Mines ParisTech at Sophia Antipolis, France) were used as model components of lignocellulosic fibers. Cotton linter (from Maeda Society), flax (Fibras-S6B, from FRD), hemp (from Chanvrière de l'Aube), sugar cane (from Centro Universitario Fundaçao Santo
André, Brazil), bamboo (grade 3, from Bamboo Fiber Technology) and coir (from Centro Universitario Fundaçao Santo André, Brazil) were used as natural fibers. The chemical composition of the fibers was determined by FRD ${ }^{\circledR}$ by solvent extraction (shown in Table 1). The standard deviation is given into brackets.

\subsection{Characterizations}

\subsubsection{Thermogravimetric analysis (TGA)}

TGA was performed under nitrogen atmosphere with a Perkin Elmer Pyris-1 Thermogravimetric Analyzer instrument. A $10 \mathrm{mg}$ sample was dried at $95^{\circ} \mathrm{C}$ during $10 \mathrm{~min}$, to evaporate the moisture, then the sample was heated from 95 to $900^{\circ} \mathrm{C}$ at $10^{\circ} \mathrm{C} / \mathrm{min}$. The char yield at $600^{\circ} \mathrm{C}$ (Res), the peak of mass loss rate (pMLR) and the temperature at pMLR $\left(T_{\mathrm{deg}}\right)$ were determined. The drying step is not taken into account in the plotted curves. So the TGA curves start at $95^{\circ} \mathrm{C}$ corresponding to a $100 \%$ of weight. All experiments were repeated three times. The temperature precision is $\pm 2^{\circ} \mathrm{C}$. The dispersion of weight measurements on the same sample was found to be approximately $5 \%$.

\subsubsection{Pyrolysis combustion flow calorimeter (PCFC)}

PCFC tests were carried out using a Fire Testing Technology (FTT) microcalorimeter. $2( \pm 1)$ mg-sample was heated under nitrogen flow up to $750^{\circ} \mathrm{C}$ at a heating rate equal to $1^{\circ} \mathrm{C} / \mathrm{s}$. Pyrolysis gases were extracted and sent to a combustion chamber in the presence of $\mathrm{N}_{2} / \mathrm{O}_{2} 80 / 20$ flow. For each experiment, sample weight was chosen carefully to ensure that $\mathrm{O}_{2}$ is always in excess. Heat release rate is calculated from the oxygen consumption according to Huggett's relation [21] (1 kg of consumed oxygen corresponds to $13.1 \mathrm{MJ}$ of heat release). Each test was performed twice.

The peak of heat release rate ( $\mathrm{pHRR}$ ), the total heat release (THR), and the effective heat of combustion (EHC) at $900^{\circ} \mathrm{C}$ were determined (combustion is believed to be complete at $900^{\circ} \mathrm{C}$ ). $\mathrm{EHC}$ is calculated as the ratio between THR and mass loss at $600^{\circ} \mathrm{C}$ measured using TGA.

In supplementary experiments, temperature of combustion was monitored between 600 and $900^{\circ} \mathrm{C}$. Therefore, combustion efficiency at a temperature $T$ is calculated as follows [22]

$\chi(T)=\frac{T H R(T)}{T H R\left(900{ }^{\circ} \mathrm{C}\right)}$

It should be reminded that pyrolysis conditions were never changed (nitrogen flow). Only the combustion efficiency was affected when the combustion temperature was modified.

All experiments were performed in triplicate. According to the constructor, the accuracy of HRR values in PCFC is around 5\%. The dispersion of the results on the same sample was within this range of variation. 
Table 2

TGA parameters of the cellulose, xylan, lignin and of several natural fibers.

\begin{tabular}{|c|c|c|c|c|}
\hline Components & $\operatorname{Res}(\% w t)$ & $\operatorname{Res}_{m r}{ }^{\mathrm{a}}(\% \mathrm{wt})$ & $T_{\operatorname{deg}}\left({ }^{\circ} \mathrm{C}\right)$ & $\operatorname{pMLR}(\% / \mathrm{min})$ \\
\hline Cellulose & 9.5 & - & 371.8 & -18.2 \\
\hline Xylan & 30.0 & - & $244.0 / 292.8$ & $-5.0 /-5.6$ \\
\hline Lignin & 56.9 & - & 356.6 & -2.1 \\
\hline Cotton linter & 18.8 & 10.7 & 356.3 & -11.7 \\
\hline Flax & 22.5 & 13.6 & 369.0 & -11.3 \\
\hline Hemp & 29.1 & 10.9 & 341.5 & -9.8 \\
\hline Sugar cane & 16.1 & 20.1 & 363.6 & -9.6 \\
\hline Bamboo & 26.2 & 22.6 & 355.4 & -8.5 \\
\hline Coconut & 29.5 & 26.5 & 341.4 & -6.6 \\
\hline
\end{tabular}

a Res $_{\mathrm{mr}}$ : char yield calculated from the rule of mixtures and based on the residue (Res) of the cellulose, xylan and lignin.

\subsubsection{Cone calorimeter test coupled with Fourier transformed infrared spectrometer (cone-FTIR)}

The cone calorimeter tests were carried out using a FTT apparatus according to ISO 5660 standard. Two samples, compression molded at 110 bars into $100 \mathrm{~mm} \times 100 \mathrm{~mm} \times 4 \mathrm{~mm}$ square sheets were exposed to a radiant heat flux of $35 \mathrm{~kW} / \mathrm{m}^{2}$. All square sheets are between 17 and $25 \mathrm{~g}$ to obtain a similar compacity for all fiber beds. Indeed, the difference of compacity and the presence of oxygen in the sample have a significant impact on the fire behavior during the cone calorimeter test. The hemp has a different compacity, due to the length of the fibers. Therefore its result is not comparable to the others. The heat release rate (HRR) was measured as function of time, and time to ignition (TTI), total heat release (THR), peak of heat release rate (pHRR) and effective heat of combustion (EHC) were determined. A FTIR spectrometer Antaris IGS from ThermoFisher Scientific was coupled to the cone calorimeter. The sampling point was located on the stack just before the sampling point to oxygen analyzer. Filters were positioned to trap soot particles. A two meters transfer line was heated at $160^{\circ} \mathrm{C}$. Temperature and pressure conditions in the gas cell were fixed at $165^{\circ} \mathrm{C}$ and 650 Torr. The evolution of the gases concentration during the fire test (especially $\mathrm{CO}$ and $\mathrm{CO}_{2}$ ) was measured using Omnic software from ThermoFisher Scientific.

All experiments were repeated three times. It is commonly agreed that the accuracy of HRR values in cone calorimeter is around $15 \%$. The dispersion of the results for the same sample was within this range.

\section{Results}

\subsection{Cellulose, xylan, lignin}

The pyrolysis of the three main components of fibers (cellulose, xylan and lignin) has been studied under nitrogen atmosphere (Fig. 1 and Table 2). These materials exhibit great differences that can be related to their chemical structure. Xylan starts to degrade earlier and decomposes in the range $220-350^{\circ} \mathrm{C}$ in two stages. The low thermal stability of xylan is assumed to be due to a lower degree of polymerization compared to cellulose and lignin [23]. Acetic acid and furfural are the main degradation products of xylan. Random repolymerization of the radicals produced during the main degradation step leads to a significant char yield at high temperature (30\%wt at $600{ }^{\circ} \mathrm{C}$ - Table 2). Cellulose is the most stable compound with a peak of mass loss rate around $370^{\circ} \mathrm{C}$. It is generally recognized that cellulose decomposes through a rapid depolymerization process by cleavage of glycosyl units leading to the formation of 1,6-anhydro-b-D-glucopyranose (levoglucosan) [12]. The char yield is only $9.5 \%$ wt at $600{ }^{\circ} \mathrm{C}$ (Table 2). The degradation of lignin occurs over a wide range of temperature $\left(200-500^{\circ} \mathrm{C}\right)$ in several steps well described in the review of Brebu et al. [24]. In a first step $\left(230-260^{\circ} \mathrm{C}\right)$, low molecular weight products resulting from the propanoid side chain cleavage are released. Then the main degradation step $\left(275-450^{\circ} \mathrm{C}\right)$ corresponds to the cleavage of the main chain either by $\mathrm{C}-\mathrm{C}$ and $\beta$-scission or by aryl-ether cleavage. At this point a large quantity of methane is evolved. Above $500^{\circ} \mathrm{C}$, further rearrangements and condensation of the aromatic structure occur, leading to the formation of a significant char yield (57\%wt at $600^{\circ} \mathrm{C}$, Table 2) and the release of dihydrogen in the gas phase. The pyrolysis of cellulose, xylan and lignin in this paper are consistent with the literature [12,23].

HRR versus temperature curves in PCFC (Fig. 2) confirm the different decomposition steps observed for cellulose, xylan and lignin by TGA measurements. Xylan starts to decompose first in two stages decomposition $\left(252\right.$ and $304^{\circ} \mathrm{C}$ ). Then the lignin decomposes at $347^{\circ} \mathrm{C}$ and finally the cellulose at $370^{\circ} \mathrm{C}$. The cellulose is the most exothermic component with a pHRR equal to $141 \mathrm{~W} / \mathrm{g}$ (against 48 and $36 \mathrm{~W} / \mathrm{g}$ for xylan and lignin, respectively) and a THR equal to $8.6 \mathrm{~kJ} / \mathrm{g}$ (against $4.5 \mathrm{~kJ} / \mathrm{g}$ for both xylan and lignin). Furthermore, PCFC allows determining the effective heat of combustion $\mathrm{EHC}_{\mathrm{exp}}$ of these compounds (Table 3 ). These results are compared to the theoretical effective heat of combustion $\left(\mathrm{EHC}_{\text {theo }}\right)$ whose calculation
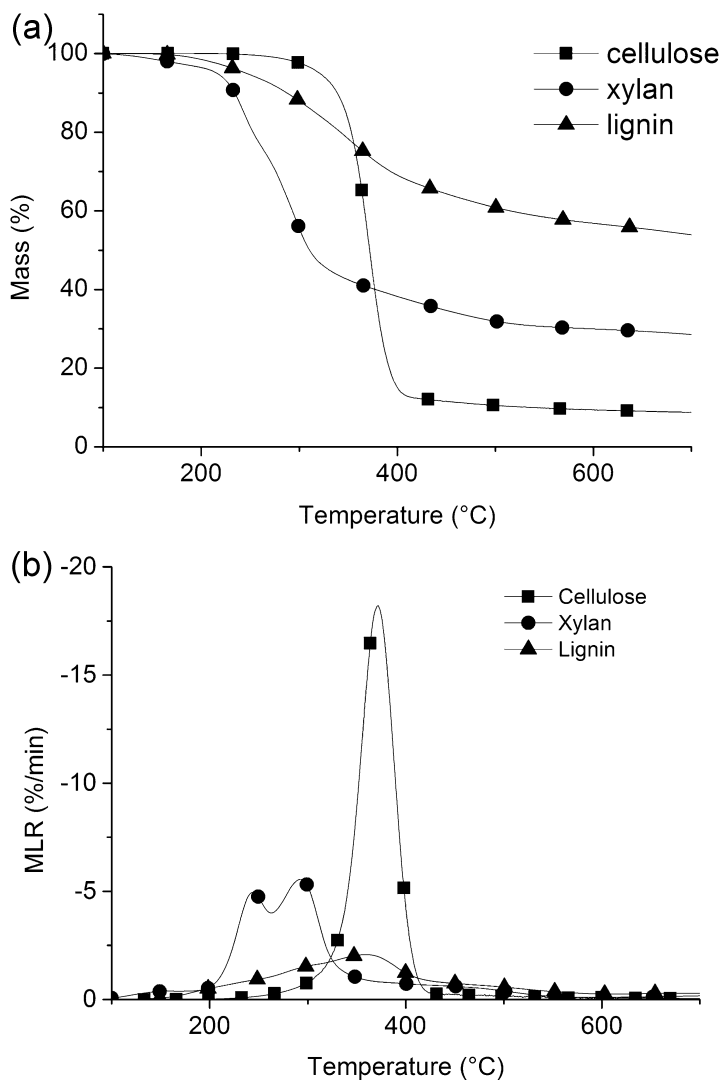

Fig. 1. Thermogravimetric analysis: (a) mass and (b) mass loss rate (MLR) versus temperature curves of cellulose, xylan and lignin. 
Table 3

PCFC parameters of cellulose, xylan, lignin and of several natural fibers.

\begin{tabular}{|c|c|c|c|c|c|c|c|}
\hline & $\operatorname{Tdeg}\left({ }^{\circ} \mathrm{C}\right)$ & pHRR (W/g) & THR (kJ/g) & $\mathrm{EHC}_{\exp }(\mathrm{kJ} / \mathrm{g})$ & $\mathrm{EHC}_{\text {theo }}{ }^{\mathrm{a}}(\mathrm{kJ} / \mathrm{g})$ & $E H C_{\text {theo }}^{\text {char b }}(\mathrm{kJ} / \mathrm{g})$ & $\mathrm{EHC}_{\mathrm{mr}}{ }^{\mathrm{c}}(\mathrm{kJ} / \mathrm{g})$ \\
\hline Cellulose & 370 & 141 & 8.6 & 9.8 & 15.5 & 13.5 & nd \\
\hline Xylan & $252 / 304$ & $35 / 48$ & 4.5 & 6.4 & 12.7 & 3.24 & nd \\
\hline Lignin & 350 & 36 & 4.5 & 10.4 & $24.9-29.3$ & 11.8 & nd \\
\hline Cotton linter & 356 & 145 & 9.1 & 11.5 & nd & nd & 8.8 \\
\hline Flax & 371 & 115 & 5.8 & 7.6 & nd & nd & 8.6 \\
\hline Hemp & 346 & 108 & 6.2 & 8.5 & nd & nd & 7.7 \\
\hline Sugar cane & 371 & 116 & 8.9 & 12.5 & nd & nd & 7.8 \\
\hline Bamboo & 365 & 104 & 8.7 & 11.8 & nd & nd & 8.1 \\
\hline Coconut & 350 & 87 & 7.3 & 10.2 & nd & nd & 8.8 \\
\hline
\end{tabular}

a Theoretical effective heat of combustion based on the reaction described in Eq. (2).

b Theoretical effective heat of combustion considering the composition variation due to the char yield.

c Effective heat of combustion calculated from the rule of mixtures and the three EHC of the cellulose, xylan and lignin.

is based on Eq. (2). In the case of complete combustion, a chemical compound containing carbon, hydrogen and oxygen undergoes oxidation that leads to $\mathrm{CO}_{2}$ and $\mathrm{H}_{2} \mathrm{O}$ release according to Eq. (2) $[25,26]$

$\mathrm{C}_{c} \mathrm{H}_{h} \mathrm{O}_{m}+\left(c+\frac{h-2 m}{4}\right) \mathrm{O}_{2} \rightarrow c \mathrm{CO}_{2}+\frac{h}{2} \mathrm{H}_{2} \mathrm{O}$

According to Huggett's relation, the heat released by the combustion is $13.1 \mathrm{~kJ}$ per gram of consumed oxygen. Thus, theoretical $\mathrm{EHC}\left(\mathrm{EHC}_{\text {theo }}\right)$ of organic compounds can be calculated. Cellulose with the chemical formula $\left(\mathrm{C}_{6} \mathrm{H}_{10} \mathrm{O}_{5}\right)_{n}$ exhibits a $E H C_{\text {theo }}$ of $15.5 \mathrm{~kJ} / \mathrm{g}$ (see details of calculation in supporting information). Xylan is a complex polysaccharide whose chemical formula can be approximated to $\left(\mathrm{C}_{5} \mathrm{H}_{8} \mathrm{O}_{5}\right)_{n}$, hence its $E H C_{\text {theo }}$ is $12.7 \mathrm{~kJ} / \mathrm{g}$. Lignin is a complex highly branched aromatic polymer. The structure of lignin is based on three main repetition units, namely p-coumaril $\left(\mathrm{C}_{9} \mathrm{H}_{10} \mathrm{O}_{2}\right)$, coniferyl $\left(\mathrm{C}_{10} \mathrm{H}_{12} \mathrm{O}_{3}\right)$ and sinapyl $\left(\mathrm{C}_{11} \mathrm{H}_{14} \mathrm{O}_{4}\right)$ units $[24,27]$. $\mathrm{EHC}_{\text {theo }}$ of lignin can be estimated between 24.9 and $29.3 \mathrm{~kJ} / \mathrm{g}$ depending on the repetition units. According to Table 3, it is obvious that $\mathrm{EHC}_{\exp }$ values are much lower than the theoretical ones. However, thermochemistry calculations (giving $\mathrm{EHC}_{\text {theo }}$ ) do not take into account the energy stored in the char. Hence these theoretical EHC can be recalculated by modifying the chemical formula of the three compounds considering that char is composed only of carbon ( $E H C_{\text {theo }}^{\text {char }}$ ) (see Appendix). According to this assumption, $E H C_{\text {theo }}^{\text {char }}$ of cellulose, xylan and lignin are $13.5,3.24$ and $11.8 \mathrm{~kJ} / \mathrm{g}$ respectively. These calculated values are closer to the experimental ones. Therefore, it can be concluded that the low values of $\mathrm{EHC}_{\exp }$ are mainly due to the charring ability of the compound that enables to store energy in the char.

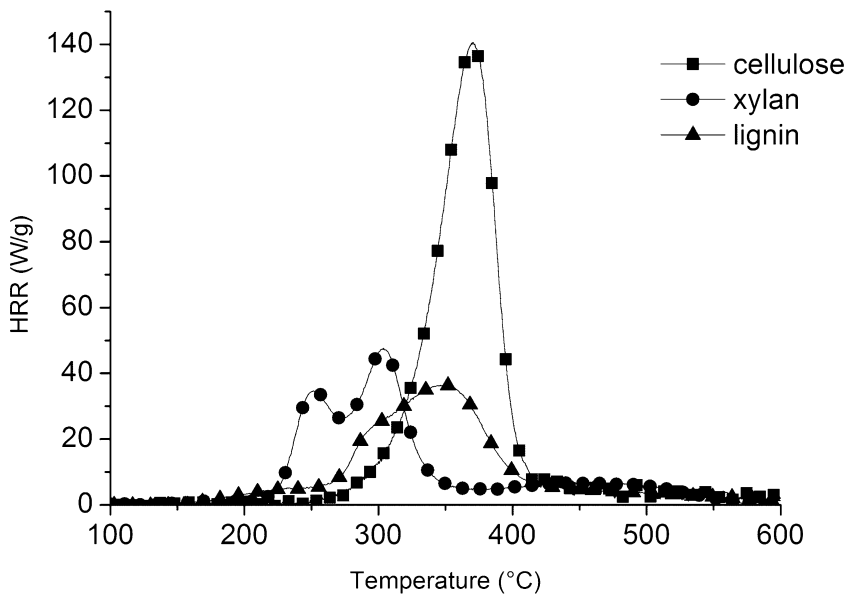

Fig. 2. PCFC curves of cellulose, xylan and lignin.
Another important parameter governing the heat release during a fire is the combustion efficiency $\chi$ (given in Eq. (1)). Combustion efficiency can be studied by PCFC by measuring the total heat release at different combustion temperatures. This method was used successfully with various polymeric materials [22]. Fig. 3 shows the variation of the combustion efficiency for the three model components of natural fibers. The combustion efficiency is equal to 1 above a critical temperature and exhibits a decrease below this temperature. It can be seen that complete combustion of lignin is attained at higher temperatures and combustion efficiency decreases more rapidly than that of xylan and cellulose.

To describe the combustion efficiency curves, a relation (Eq. (3)) analogous to Avrami equation for crystallization kinetics was proposed [22], $A$ and $n$ being adjustable parameters without any physical sense

$\chi(T)=1-\exp \left(-A T_{C}^{n}\right)$

Rearranging Eq. (3) leads to the following equation:

$\ln (-\ln (1-\chi(T)))=\ln A+n \ln T_{C}$

with $\chi(T)$ is the combustion efficiency, $T_{C}$ is the combustion temperature.

Thus, plotting $\ln (-\ln (1-\chi(T)))$ versus $T_{C}$ should be a straight line with slope $n$ and intercept $\ln A$.

Fig. 4 and Table 4 show the variation of $n$ versus $\ln A$ for the three basic compounds. Similarly to what we observed in the previous study [22] with various polymers, a linear relation is obtained. In the above-mentioned paper, we observed that aliphatic polymers such as LDPE or EVA exhibit a low $n$ value (around 8 for LDPE)

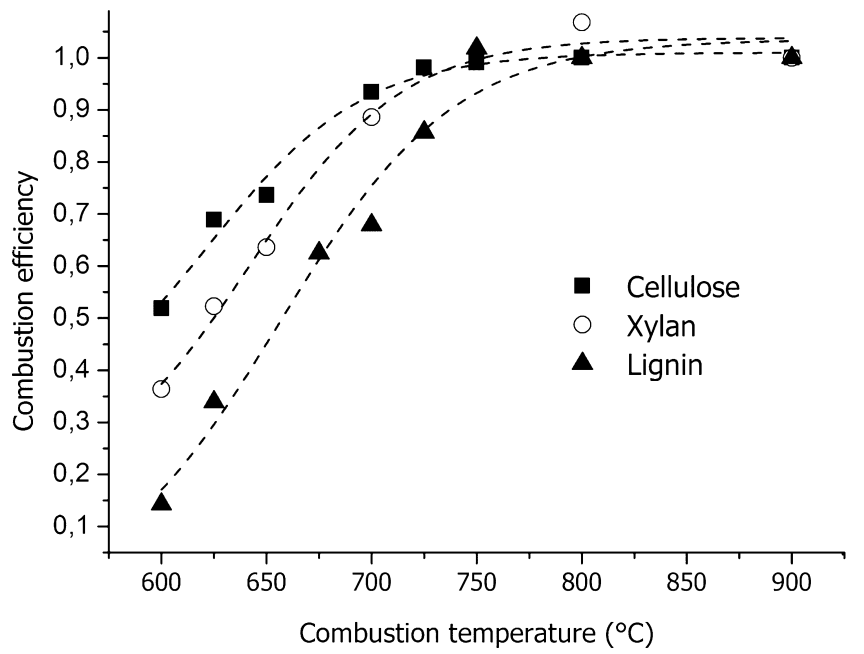

Fig. 3. Evolution of combustion efficiency $\chi$ of cellulose, xylan and lignin versus the combustion temperature using PCFC. 


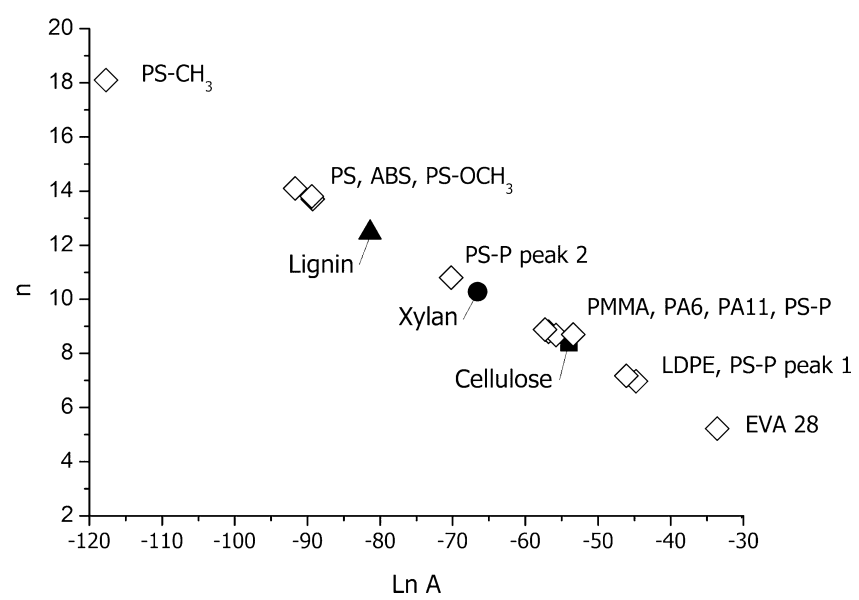

Fig. 4. $n=f(\ln A)$ for the three model components (full symbols) and classically used polymers (empty symbols).

contrary to the styrenic polymers, which exhibit high $n$ values (around 14 for the PS). The value of $n$ for cellulose is comparable to that obtained for LDPE while that of lignin, is around 12, and is comparable to that of PS. These results seem to highlight that $\mathrm{n}$ depends on the aliphatic or aromatic structure of the considered polymer (Table 4). Xylan, which exhibits an aliphatic structure with only some aromatic pendant groups, confirms this assertion with an intermediate $\mathrm{n}$ parameter.

Lyon et al. [28,29] used a similar approach to that of Sonnier's one [22] (Eq. (3)) but replaced the phenomenological power law by an Arrhenius law (Eq. (5))

$\chi(T)=1-\exp \left(-B \tau \exp \left(-\frac{E_{a}}{R T_{C}}\right)\right)$

Rearranging Eq. (5) leads to the following equation:

$\ln (-\ln (1-\chi(T)))=\ln B \cdot \tau+\frac{E_{a}}{R T_{C}}$

Thus, plotting $\ln (-\ln (1-\chi(T)))$ versus $T_{C}$ gives a straight line with slope $E_{a} / R$ and intercept $\ln (B \cdot \tau)$.

In Lyon's expression, $\tau, B$ and $E_{a}$ represent respectively the residence time in the combustor, the global frequency factor and the activation energy of oxidation reaction. PCFC data of cellulose, xylan and lignin have been analyzed using Eqs. (5) and (6). Activation energy $E_{a}$ as well as pre-exponential factor $B \tau$ are listed in Table 4. These results confirm that lignin exhibits the highest activation energy for combustion reaction $(165 \mathrm{~kJ} / \mathrm{mol})$ whereas cellulose exhibits the lowest $E_{a}(92 \mathrm{~kJ} / \mathrm{mol})$. These values are somewhat contradictory with those obtained from TGA by several authors in the literature [27]. However, it is not sure that the two methods can be compared. Indeed in TGA the degradation of cellulose occurs at low temperature $\left(<600^{\circ} \mathrm{C}\right)$. However, as proved by Fig. 3, below $600^{\circ} \mathrm{C}$ the combustion efficiency is very low indicating that combustion is

Table 4

Combustion efficiency parameters for cellulose, xylan, lignin and several natural fibers.

\begin{tabular}{llrcc}
\hline Samples & \multicolumn{1}{l}{$\ln A$} & \multicolumn{1}{c}{$n$} & $E_{a}(\mathrm{~kJ} / \mathrm{mol})$ & $10^{-3} B \cdot \tau$ \\
\hline Cellulose & -52.6 & 8.2 & 92.6 & 256 \\
Xylan & -64.8 & 10.0 & 109.2 & 1,574 \\
Lignin & -80.8 & 12.4 & 165.1 & 993,619 \\
Cotton linter & -35.4 & 5.0 & 61.8 & 3.7 \\
Flax & -59.9 & 9.3 & 97.2 & 393 \\
Hemp & -66.1 & 10.2 & 89.7 & 113 \\
Sugar cane & -66.1 & 10.3 & 109.5 & 2,484 \\
Bamboo & -57.2 & 8.9 & 112.1 & 2,744 \\
Coconut & -70.6 & 11.0 & 119.7 & 9,338 \\
\hline
\end{tabular}
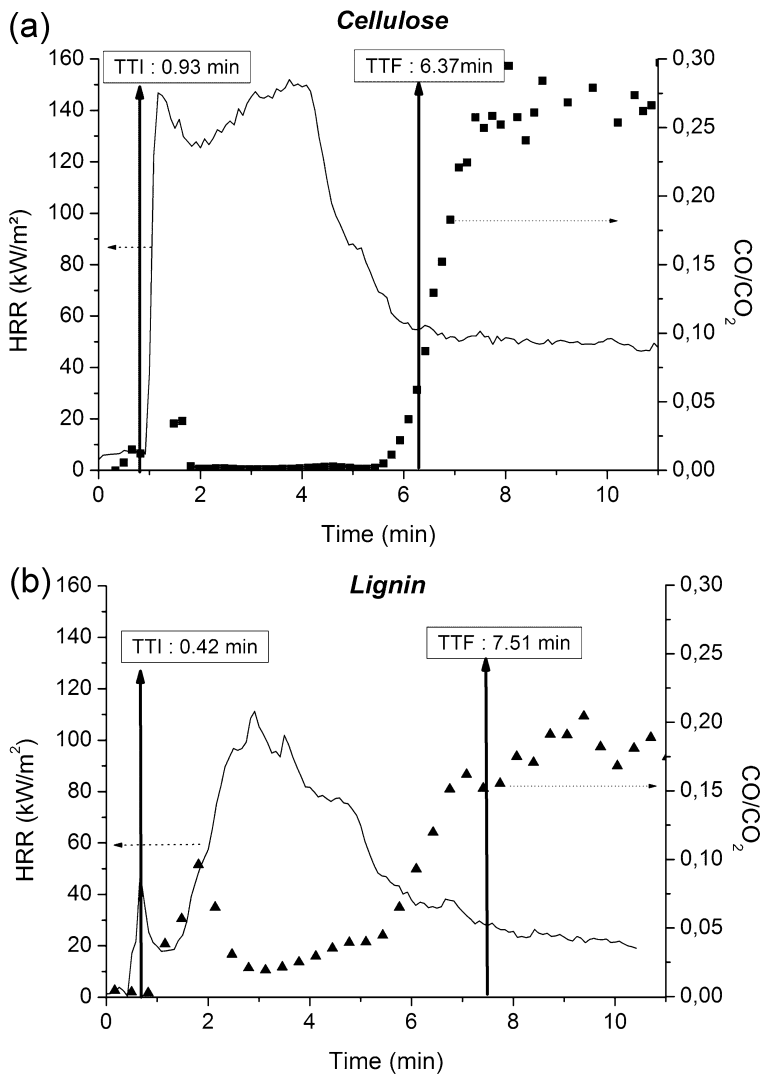

Fig. 5. HRR versus time and $\mathrm{CO} / \mathrm{CO}_{2}$ ratio obtained during the cone calorimeter test of (a) cellulose and (b) lignin.

largely incomplete. Thus, the term "thermo-oxidative degradation" would be more appropriate.

Cone calorimetry is probably the most frequently used technique to study the fire behavior of materials at bench-scale. It enables highlighting specific physical phenomena affecting burning (e.g. barrier effect) that do not occur in small scale tests (TGA or PCFC). HRR cone curves of cellulose and lignin, which have respectively the lowest and the highest activation energy of combustion and $n$ parameter, are presented in Fig. 5. The completeness of combustion was also assessed by the $\mathrm{CO} / \mathrm{CO}_{2}$ ratio determined by FTIR coupling. It can be noted that lignin exhibits a shorter time to ignition (compared to cellulose, with the same compacity around $0.4-0.5 \mathrm{~g} / \mathrm{cm}^{3}$ ), that can be related to the low decomposition onset as shown by TGA. Once ignited, lignin shows a low HRR as well as a relatively high $\mathrm{CO} / \mathrm{CO}_{2}$ ratio. Cellulose exhibits a higher HRR that reaches rapidly a value of $140 \mathrm{~kW} / \mathrm{m}^{2}$ and keeps almost constant during several minutes before decreasing when depletion of fuels occurs. $\mathrm{CO} / \mathrm{CO}_{2}$ ratio is very low during burning. It could be assumed that these results are in good agreement with those obtained in PCFC.

It should be underlined that char residues of both cellulose and lignin undergo thermo-oxidation after flame out, leading to a persistent heat release and a significant increase of $\mathrm{CO} / \mathrm{CO}_{2}$ ratio.

\subsection{Natural fibers}

The natural fibers are mainly composed of cellulose, hemicellulose and lignin. This part investigates the relation between the chemical composition of natural fibers, and their pyrolysis and combustion.

The non-oxidative pyrolysis of natural fibers (Fig. 6) has been widely studied in the literature. It occurs in four principal steps 

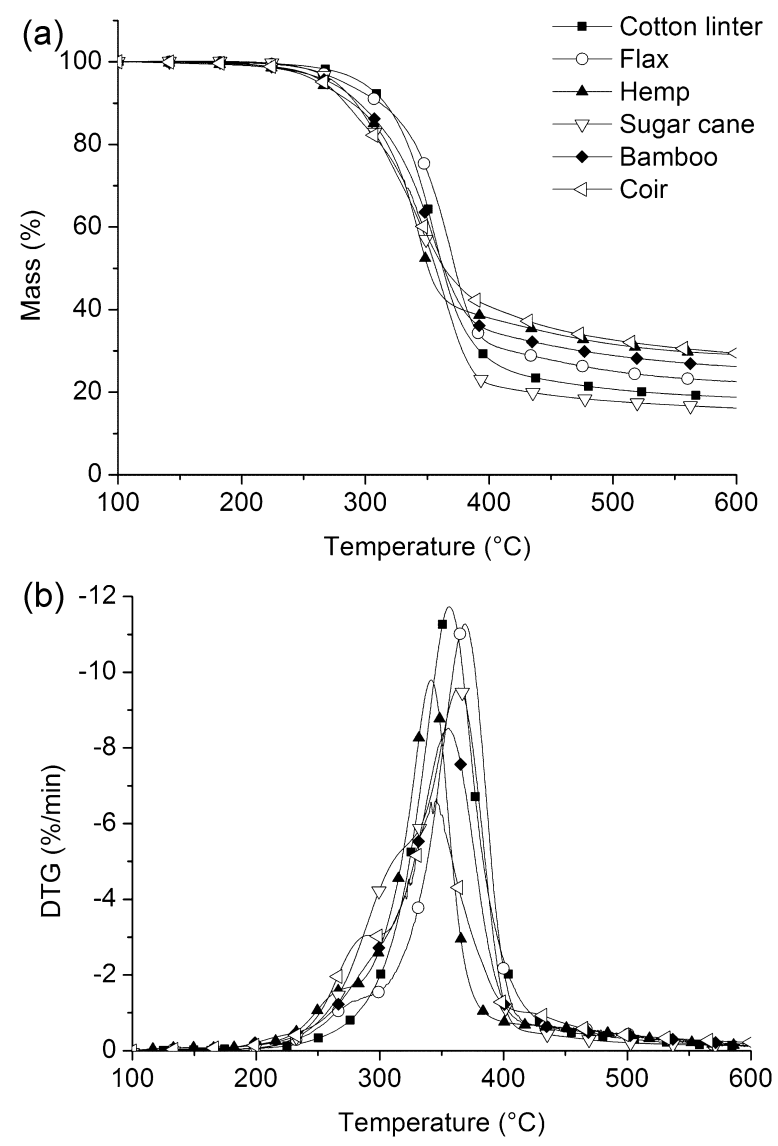

Fig. 6. TGA curves of several natural fibers.

$[6,14,30,18,31]$. The first stage of decomposition in the temperature range $50-150^{\circ} \mathrm{C}$ corresponds to the release of water absorbed by the natural fibers. In this study, this stage is not seen because fibers have been dried before testing. The second stage of degradation around $250-370^{\circ} \mathrm{C}$ corresponds to the decomposition of hemicellulose. Then the main stage of degradation between 340 and $370{ }^{\circ} \mathrm{C}$ corresponds to the degradation of the $\alpha$-cellulose by depolymerization. The last stage is the degradation of lignin, over a large range of temperature $\left(200-500^{\circ} \mathrm{C}\right)$.

From TGA measurements (Fig. 6 and Table 2) of lignocellulosic fibers, the temperature of the main decomposition step corresponding to cellulose decomposition is shifted to lower

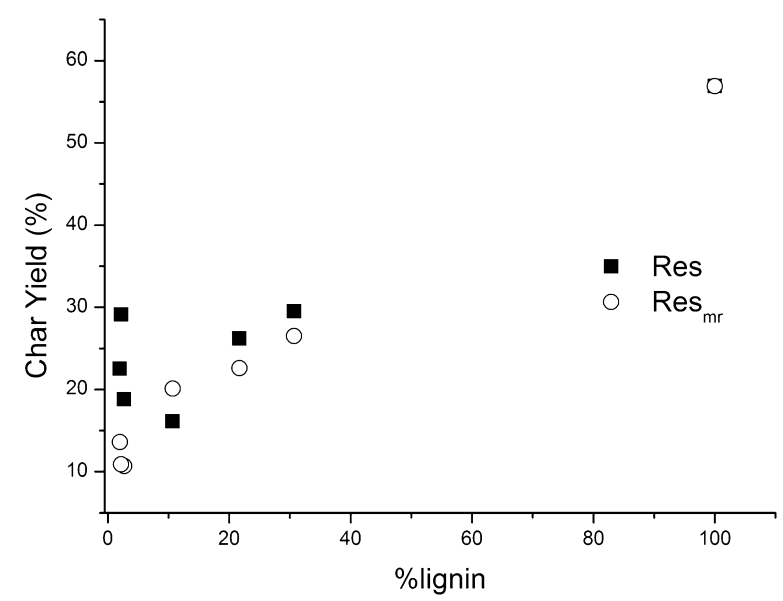

Fig. 7. Comparison of the experimental and calculated char yields from the rule of mixture (Res and Res $_{\mathrm{mr}}$, respectively).
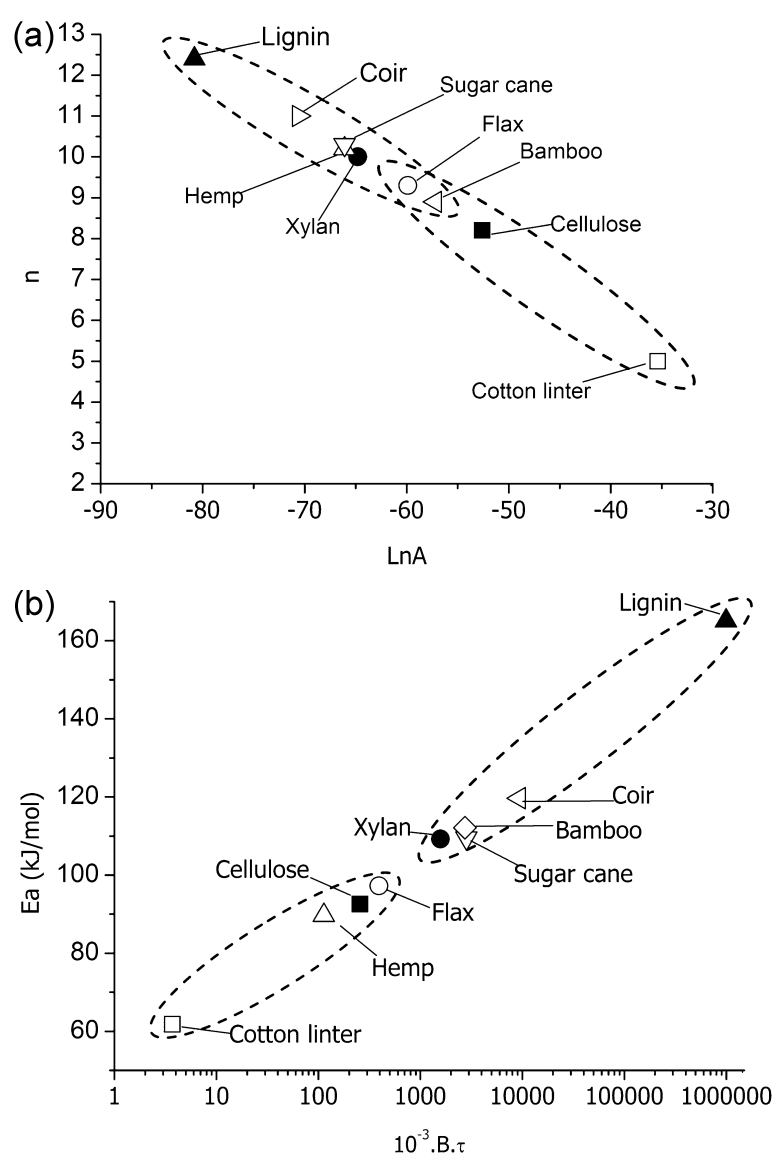

Fig. 8. (a) $n=f(\ln A)$ and (b) $E_{a}=f\left(10^{-3} \cdot B \tau\right)$ for the studied natural fibers and the three model components.

temperature. This result indicates an interaction between cellulose and lignin during decomposition. A decrease of the peak of mass loss rate is also evidenced. Furthermore, lignin influences the char yield. The theoretical char yields of natural fibers have been calculated from the amount of cellulose, xylan and lignin using the rule of mixtures ( Res $_{\mathrm{mr}}$ given in Table 1). From Fig. 7, at lignin content higher than $10 \%$ wt low differences are observed. However a significant mismatch between theoretical and experimental char yields can be remarked at low lignin content $(<10 \% \mathrm{wt})$. These results lead to conclude that lignin influences the degradation pathway of cellulose, especially at low content. Such interactions have already been mentioned by Hosaya et al. [32]. However, these authors claimed that lignin promotes depolymerization and reduces char yield. In the above mentioned paper the ratio 2:1 (cellulose: lignin) was used. In our case an opposite effect was observed, but at low content of lignin (around 40:1 cellulose/lignin ratio) [32]. The presence of a low amount of lignin seems to change the cellulose degradation pathway, promoting dehydration and further char formation at the expense of depolymerization. It has been shown in the literature that acidic catalysts are likely to enhance dehydration reaction and charring [33,34]. For example, Dobele et al. [33] have shown that cellulose impregnated with phosphoric acid gives dehydrated cyclic structures in the solid phase during pyrolysis. Furthermore, the catalytic effect of acids on cellulose charring has been largely used to improve the flame retardancy of cellulosic fabrics [35]. Lignin is not an acid but it gives off acids as it deteriorates. Brebu et al. [24] mentioned that acetic acid is one of the most important fragment released during lignin decomposition. Syringic, p-coumaric and vanillic acids can also be evolved. These acids are likely to be released from $200^{\circ} \mathrm{C}$ during lignin pyrolysis [36]. Therefore it may be assumed that, in lignocellulosic fibers, 
lignin plays the role of acidic catalyst favoring cellulose dehydration and charring.

$\mathrm{EHC}_{\mathrm{mr}}$ calculated according to a linear rule of mixtures using values for cellulose, xylan and lignin are reported in Table 3. Values are similar for all natural fibers ranging from 7.7 to $8.8 \mathrm{~kJ} / \mathrm{g}$. Experimental EHC are in the same order of magnitude but, slightly higher $(7.6-12.5 \mathrm{~kJ} / \mathrm{g})$. A hypothesis is that the experimental char yield of natural fibers, obtained in TGA, is higher than the values calculated from the rule of mixtures. So the composition of the experimental char changes and could induce a modification of $\mathrm{EHC}_{\text {exp. }}$.

The combustion efficiency of natural fibers versus combustion temperature has also been determined using PCFC. The curves have been fitted using the two previously described equations (Eqs. (3) and (5)). The fitting parameters are presented in Fig. 8. Whatever the equation, the results are relatively similar. $E_{a}$ values for natural fibers are comprised between 90 and $120 \mathrm{~kJ} / \mathrm{mol}$ (except cotton linter), i.e. between the lower and upper limits represented respectively by cellulose and lignin. Two groups of fibers can be distinguished: those containing a low content of lignin whose activation energy is very close to that of the cellulose and those

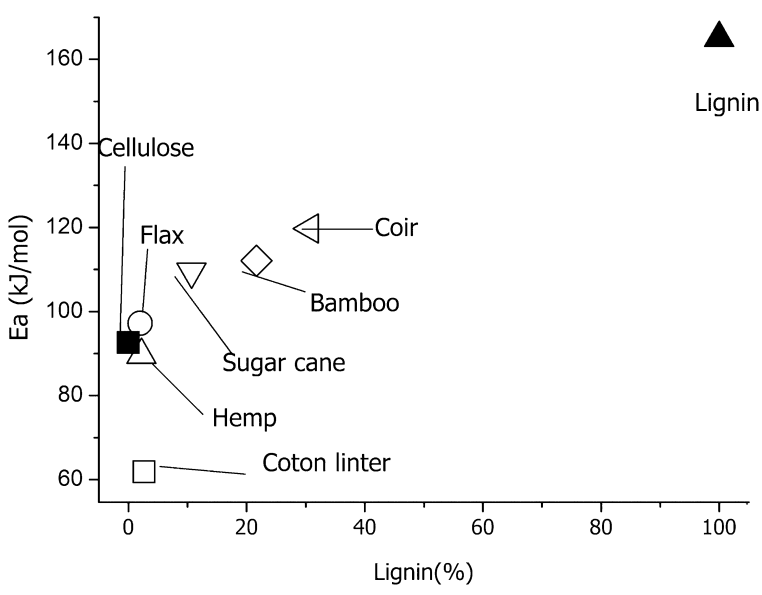

Fig. 9. $E_{a}=f(\%$ lignin $)$ for the studied natural fibers and the three model components.
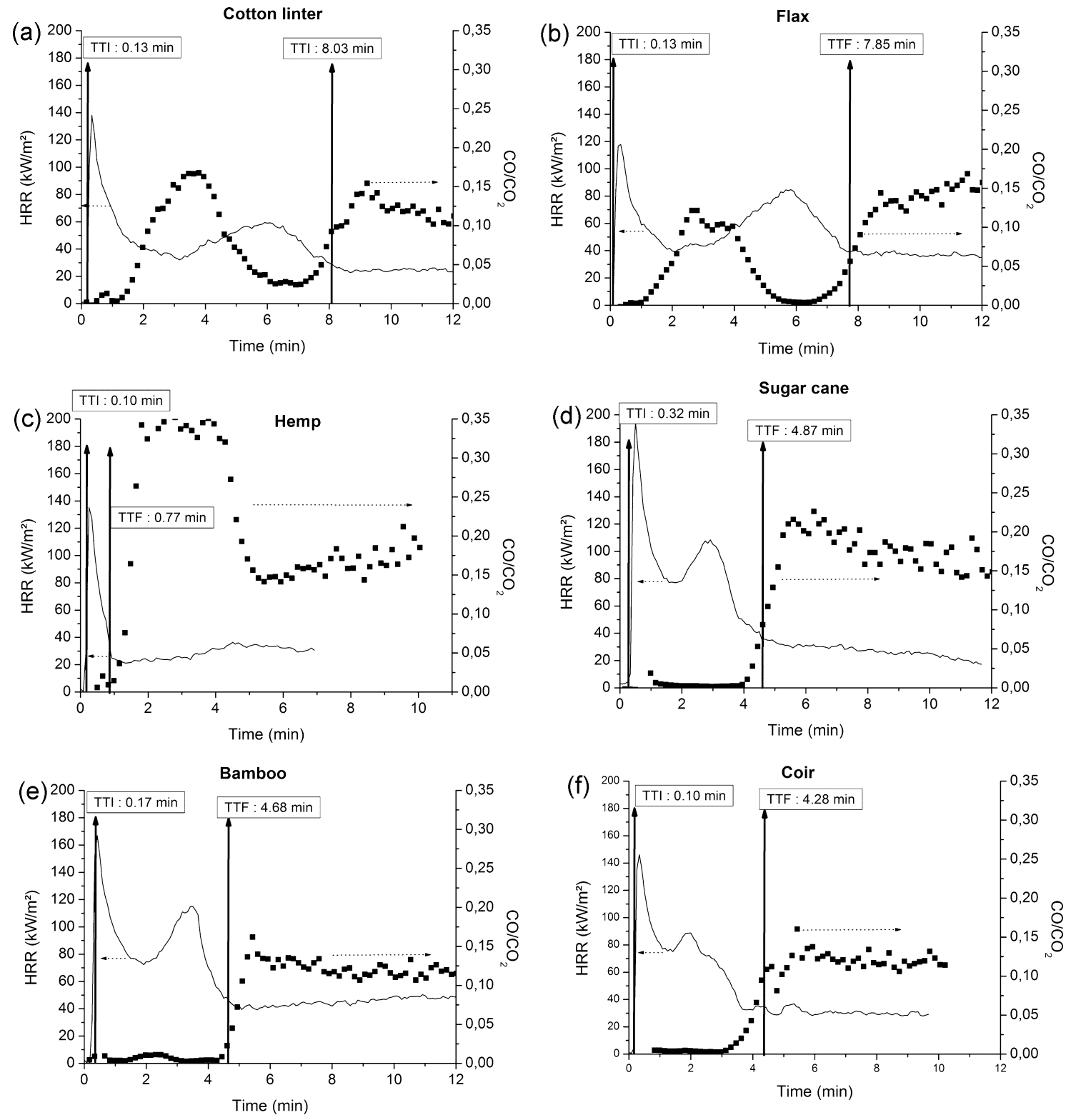

Fig. 10. HRR versus time and $\mathrm{CO} / \mathrm{CO}_{2}$ ratio obtained during cone calorimeter test of (a) cotton linter, (b) flax, (c) hemp, (d) sugar cane, (e) bamboo and (f) coir. 
Table 5

Cone calorimeter results of studied natural fibers.

\begin{tabular}{|c|c|c|c|c|c|c|}
\hline Natural fibers & $\operatorname{TTI}(\mathrm{s})$ & $\operatorname{pHRR}\left(\mathrm{kW} / \mathrm{m}^{2}\right)$ & $\mathrm{THR}_{\mathrm{TOF}}(\mathrm{kJ} / \mathrm{g})$ & $\mathrm{EHC}(\mathrm{kJ} / \mathrm{g})$ & Char (\%) & $\operatorname{Res}(\mathrm{TGA})(\%)$ \\
\hline Cotton linter & 8 & 138 & 7.6 & 9.1 & 20.7 & 18.8 \\
\hline Flax & 8 & 118 & 8.9 & 9.3 & 15.8 & 22.5 \\
\hline Hemp & 6 & 135 & $-{ }^{a}$ & $-{ }^{a}$ & $-a^{a}$ & 29.1 \\
\hline Sugar cane & 19 & 195 & 10.9 & 12.6 & 21.0 & 16.1 \\
\hline Bamboo & 10 & 167 & 9.4 & 11.4 & 23.3 & 26.2 \\
\hline Coconut & 6 & 146 & 9.0 & 12.9 & 23.6 & 29.5 \\
\hline
\end{tabular}

a Since the burning time of hemp was very short, these values were not considered.

containing a higher lignin content whose activation energy is in the range of $110-120 \mathrm{~kJ} / \mathrm{mol}$ (Fig. 8).

A good correlation between the activation energy and the lignin content is observed (except for the cotton linter) confirming that activation energy is governed by the composition of fibers and particularly the content of lignin (Fig. 9).

Cone calorimeter tests have been performed on sheets prepared by compression molding for studied natural fibers (Fig. 10). It should be noted that all fibers exhibit shorter time to ignition compared to cellulose or lignin. This could be due to the presence of xylan as pointed out by TGA and PCFC measurements. The shape of HRR curves reveals that all natural fibers exhibit a thick charring behavior according to the classification of Schartel and Hull [37]. The second peak may be caused by a cracking of the char or an increase in the effective pyrolysis due to the presence of the glass wool supporting the sample which prevents from heat transfer to the sample holder as the pyrolysis zone approaches it. After ignition, two types of behavior can be distinguished. It can be noted that hemp is not comparable to the other natural fibers because the compacity of this sample is very different. A first set of curves comprises fibers with high lignin content (sugar cane, bamboo, coir, Fig. 10d-f). For this group, a peak of HRR is rapidly reached, then HRR remains in the range $80-120 \mathrm{~kW} / \mathrm{m}^{2}$ before decreasing to $40 \mathrm{~kW} / \mathrm{m}^{2}$ at flame out. HRR keeps constant for several minutes after extinction due to the thermal oxidation of char. It can be noticed that during flaming the ratio $\mathrm{CO} / \mathrm{CO}_{2}$ is very low which indicates a relatively complete combustion. Incidentally, the effective heat of combustion is around $13 \mathrm{~kJ} / \mathrm{g}$ (Table 5 ) in good agreement with values obtained with PCFC at $T_{C}=900^{\circ} \mathrm{C}$ (Table 3) when combustion is believed to be complete. The second set of curves comprises fibers with low lignin content (Flax, cotton linter, Fig. 10a and b). For this group, HRR exhibits a peak followed by a quick decrease to very low value around $40 \mathrm{~kW} / \mathrm{m}^{2}$. Flame out occurs for longer time compared to the preceding group. During flaming, a peak of $\mathrm{CO}$ release is observed indicating an incomplete combustion. Consequently, the effective heat of combustion is relatively lower (around $9 \mathrm{~kJ} / \mathrm{g}$, Table 5 ). The $\mathrm{CO} / \mathrm{CO}_{2}$ ratio of cellulose is very low comparing to that of lignin, but surprisingly this ratio is high for the fibers with low content of lignin.

However, these results seem to be consistent with phenomena evidenced by TGA. It could be assumed that the presence of a small amount of lignin affects the degradation pathway of cellulose from depolymerization to dehydration inducing a char yield higher than expected. This charring effect and the incomplete combustion of fibers which present a low content of lignin with a high content of cellulose limit the contribution to heat and burning.

\section{Conclusion}

The aim of this study was to correlate the chemical composition of natural fibers with their pyrolysis and combustion properties. Four parameters have been selected: char yield, EHC, activation energy of combustion and $\mathrm{CO} / \mathrm{CO}_{2}$ ratio in cone calorimeter. It was shown that these parameters were closely correlated to the lignin content in the fibers. Hence, the char yield as well as the activation energy of combustion was highlighted to increase with increasing lignin content while $\mathrm{CO} / \mathrm{CO}_{2}$ ratio during flaming decreases. These beneficial effects on fire performance were balanced by an increase of EHC. No clear correlation was found between the selected parameters and the other components of fibers.

A particular interaction between cellulose and lignin was evidenced for flax, hemp and cotton linter fibers. A significant mismatch between experimental and theoretical values of char yield was found at low lignin content. The presence of a low content of lignin would impinge the cellulose degradation pathway, leading to the promotion of a char yield higher than expected. In cone calorimeter tests, fibers with low lignin content exhibit an interesting behavior with a low pHRR (that results from the low EHC of cellulose) and a long burning time that results from the char layer induced by the interaction between cellulose and lignin. To conclude the low lignin content fibers (flax and hemp) are those having the best fire behavior.

\section{Appendix A. Supplementary data}

Supplementary data associated with this article can be found, in the online version, at http://dx.doi.org/10.1016/j.jaap.2014.03.017.

\section{References}

[1] M.J. John, S. Thomas, Biofibres and biocomposites, Carbohydr. Polym. 71 (2008) 343-364.

[2] O. Faruk, A.K. Bledki, H.P. Fink, M. Sain, Biocomposites reinforced with natural fibers: 2000-2010, Prog. Polym. Sci. 37 (2012) 1552-1596.

[3] M.J. John, R.D. Anandjiwala, Recent developments in chemical modification and characterization of natural fiber-reinforced composites, Polym. Compos. 29 (2008) 187-207.

[4] R. Kozłowski, M. Władyka-Przybylak, Flammability and fire resistance of composites reinforced by natural fibers, Polym. Adv. Technol. 19 (2008) 446-453.

[5] G.G. Dorez, A. Taguet, L. Ferry, J.M. Lopez-Cuesta, Thermal and fire behavior of natural fibers/PBS biocomposites, Polym. Degrad. Stab. 98 (2012) 87-95.

[6] L.B. Manfredi, E.S. Rodríguez, M. Wladyka-Przybylak, A. Vázquez, Thermal degradation and fire resistance of unsaturated polyester, modified acrylic resins and their composites with natural fibres, Polym. Degrad. Stab. 91 (2006) $255-261$.

[7] R. Gottipati, S. Mishra, A kinetic study on pyrolysis and combustion characteristics of oil cakes: effect of cellulose and lignin content, J. Fuel Chem. Technol. 39 (2011) 265-270.

[8] A. Gani, I. Naruse, Effect of cellulose and lignin content on pyrolysis and combustion characteristics for several types of biomass, Renew. Energy 32 (2007) 649-661.

[9] R. Font, J. Moltó, A. Gálvez, M.D. Rey, Kinetic study of the pyrolysis and combustion of tomato plant, J. Anal. Appl. Pyrolysis 85 (2009) 268-275.

[10] D.K. Shen, S. Gu, A.V. Brigwater, The thermal performance of the polysaccharides extracted from hardwood: cellulose and hemicelluloses, Carbohydr. Polym. 85 (2010) 39-45

[11] V. Pasangulapati, D. Ramachandriya, A. Kumar, M.R. Wilkins, C.L. Jones, R.L. Huhnke, Effects of cellulose, hemicellulose and lignin on thermochemical conversion characteristics of the selected biomass, Bioresour. Technol. 114 (2012) 663-669.

[12] K. Cheng, W.T. Winter, A.J. Stipanovic, A modulated-TGA approach to the kinetics of lignocelluloseic biomass pyrolysis/combustion, Polym. Degrad. Stab. 97 (2012) 1606-1615

[13] H. Yang, R. Yan, H. Chen, D.H. Lee, C. Zheng, Characteristics of hemicellulose, cellulose and lignin pyrolysis, Fuel 86 (2007) 1781-1788.

[14] R. Moriana, F. Vilapana, S. Karlsson, A. Ribes-Greus, Improved thermomechanical properties by the addition of natural fibres in starch-based sustainable biocomposites, Comp. Appl. Sci. Manuf. 42 (2011) 30-40. 
[15] K. Raveendran, A. Ganesh, K.C. Khilar, Pyrolysis characteristics of biomass and biomass components, Fuel 75 (1996) 987-998.

[16] J.J. Manya, E. Velo, L. Puigjaner, Kinetics of biomass pyrolysis: a reformulated three-parallel-reactions model, Ind. Chem. Res. 42 (2003) 434-441.

[17] D. Di Blasi, Combustion and gasification rates of lignocellulosic chars, Prog. Energy Combust. Sci. 35 (2009) 121-140.

[18] S. Chapple, R. Anandjiwala, Flammability of natural fiber-reinforced composites and strategies for fire retardancy: a review, J. Thermoplast. Compos. 23 (2010) 871-893.

[19] J.Y. Jang, T.K. Jeong, H.J. Oh, J.R. Youn, Y.S. Song, Thermal stability and flammability of coconut fiber reinforced poly(lactic acid) composites, Comp. Eng. 43 (2012) 2434-2438.

[20] D. Dood, I.K.O. Cann, Enzymatic deconstruction of xylan for biofuel production, Bioenergy 1 (2009) 2-17.

[21] C. Huggett, Estimation of heat release by means of oxygen consumption measurement, Fire Mater. 4 (1980) 61-65.

[22] R. Sonnier, B. Otazaghine, L. Ferry, J.M. Lopez-Cuesta, Study of the combustion efficiency of polymers using a pyrolysis - combustion flow calorimeter, Combust. Flame 160 (2013) 2182-2193.

[23] S. Wang, B. Ru, H. Lin, Z. Luo, Degradation mechanism of monosaccharides and xylan under pyrolytic conditions with theoretic modeling on the energy profiles, Bioresour. Technol. 143 (2013) 378-383.

[24] M. Brebu, C. Vasile, Thermal degradation of lignin - a review, Cellul. Chem. Technol. 44 (2010) 353-363.

[25] R. Lyon, M. Jansen, Polymer flammability, DOT/FAA/AR-05/14, 2005.

[26] A.L. Sullivan, R. Ball, Thermal decomposition and combustion chemistry of cellulosic biomass, Atmos. Environ. 47 (2012) 133-141.
[27] J. Li, B. Li, X. Zhang, Comparative studies of thermal degradation between larch lignin and Manchurian ash lignin, Polym. Degrad. Stab. 78 (2002) 279-285.

[28] R. Lyon, R. Walters, S. Stoliatov, A thermal analysis method for measuring polymer flammability, J. ASTM. 4 (2003) 1-18.

[29] R. Lyon, R. Walters, Gas phase combustion studies of flame retardant polymers in the microscale combustion calorimeter, in: 24th Annual Conference on Recent Advances in Flame Retardancy Polymeric Materials, Stamford, 2013.

[30] C. Albano, J. Gonzalez, M. Ichazo, D. Kaiser, Thermal stability of blends of polyolefins and sisal fiber, Polym. Degrad. Stab. 66 (1999) 179-190.

[31] K.C. Manikandan Nair, S. Thomas, G. Groeninck, Thermal and dynamic mechanical analysis of polystyrene composites reinforced with short sisal fibres, Compos. Sci. Technol. 61 (2001) 2519-2529.

[32] T. Hosoya, H. Kawamoto, S. Saka, Cellulose-hemicellulose and cellulose-lignin interactions in wood pyrolysis at gasification temperature, J. Anal. Appl. Pyrolysis 80 (2007) 118-125.

[33] G. Dobele, G. Rossinskaya, G. Telysheva, D. Meier, O. Faix, Cellulose dehydration and depolymerisation reactions during pyrolysis in the presence of phosphoric acid, J. Anal. Appl. Pyrolysis 49 (1999) 307-317.

[34] H. Ohtani, T. Komura, N. Sonoda, Y. Taguchi, Evaluation of acidic paper deterioration in library materials by pyrolysis-gas chromatography, J. Anal. Appl. Pyrolysis 85 (2009) 460-464.

[35] S. Gaan, G. Sun, Effect of phosphorus flame retardants on thermo-oxidative decomposition of cotton, Polym. Degrad. Stab. 92 (2007) 968-974.

[36] M. Brebu, T. Tamminen, I. Spiridon, Thermal degradation of various lignins by TG-MS/FTIR and Py-GC-MS, J. Anal. Appl. Pyrolysis 104 (2013) 531-539.

[37] B. Schartel, T.R. Hull, Development of fire-retarded materials-Interpretation of cone calorimeter data, Fire Mater. 31 (2007) 327-354. 